\title{
Türkiye’deki Hava Taşımacılığı Üzerine Bir Tahminleme Çalışması
}

\section{A Forecasting Study on Air Transportation in Turkey}

\author{
Çiğdem Kalathilparmbil, ${ }^{a *}$ Özlem Şahin ${ }^{\mathrm{b}}$ \\ a Öğr. Gör. Dr., Eskişehir Teknik Üniversitesi, Fen Fakültesi, İstatistik Bölümü, 26210, Eskişehir/Türkiye. \\ ORCID: 0000-0002-6910-1008
}

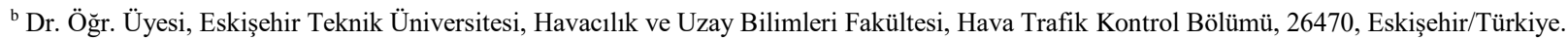
ORCID: 0000-0002-9632-5533

\section{MAKALE BILGİSI}

\section{Makale Geçmişi:}

Başvuru tarihi: 10 Ağustos 2018

Düzeltme tarihi: 03 Aralık 2018

Kabul tarihi: 02 Ocak 2019

\section{Anahtar Kelimeler:}

Hava Taşımacılığı

Uçak Trafiği

Yolcu Trafiği

Yük Trafiği

Eğri Uydurma

\section{ARTICLE INFO}

\section{Article history:}

Received 10 august 2018

Received in revised form 03 Descember 2018

Accepted 02 January 2019

\section{Keywords:}

Air Transportation

Flight Traffic

Passenger Traffic

Freight Traffic

Curve Fitting

\section{ÖZ}

Planlama ve kontrol işlemlerinde tahminleme önemli bir araçtır. Gelecekteki belirsizliklerin aydınlanması, değerlendirilmesi, önlemlerin alınması açısından tahmin yani öngörü, kritik bir rol oynamaktadır. Özellikle hava taşımacılığı gibi sürekli büyüyen bir sektörde de gelecek için öngörünün yapılarak planlamanın gerçekleştirilmesi her açıdan önemlidir. Bu nedenle öncelikle Devlet Hava Meydanları İşletmesi (DHMI)'nin Türkiye genelindeki havalimanları için yayımladığı istatistikler doğrultusunda 2002-2017 yıllarına ait iç hat, dış hat ve toplam olmak üzere uçak, yolcu ve yük trafiğinden oluşan bir veri seti hazırlanmıştır. Bu veri seti yardımıyla çalışmada, hızla büyüyen hava taşımacılığı için 2018-2023 yılları arasındaki uçak, yolcu ve yük trafik sayılarının eğri uydurma yöntemi kullanılarak tahmin edilmesi amaçlanmıştır. Elde edilen tahmin sonuçları 2019 ve 2020 yılları için DHMİ'nin tahminleri ile karşılaştırılmış ve sonuçların birbirine yakın olduğu gözlenmiştir.

\section{A B S T R A C T}

Forecasting is a significant tool for planning and controlling processes. It plays a critical role in enlightening, evaluating, and taking measures for future uncertainties. It is also important in every respect to realize the planning for the future in a continuously growing air transportation industry. In this study, a data set; including domestic, international and total aircraft movements, passenger and freight is prepared by using the published statistics of General Directorate of State Airport Authority for the years between 2002-2017. By using the curve fitting method, forecasting the number of the domestic, international and total aircraft movements, passenger and freight, between 2018-2023, is aimed. The obtained forecasting results are compared to DHMI's forecasting results. The close results are observed.

\section{Giriş}

Havayolu taşımacılığı, ulaştırma sistemi içerisinde emniyetli, güvenilir, hızlı ve hizmet kalitesi açısından daha memnun edici olması nedeniyle insanlar için giderek daha fazla tercih edilmektedir. Özellikle iş amacıyla çıkılan seyahatlerde daha da önem kazanmaktadır. Yolcu talebinin giderek artması ile operasyondaki uçak sayısı da eş zamanlı olarak artış göstermektedir. Her yıl giderek büyüyen hava taşımacılığı için gelecekte karşılaşılabilecek her türlü sorun ve talep önceden belirlenmelidir. Gelecekteki belirsizlikler için yapılacak en iyi tahminleme yani öngörü ile bundan sonraki adımların ihtiyaçlara yönelik olarak daha iyi şekilde planlanması sağlanabilecektir. Planlamanın yapılabilmesi

\footnotetext{
** Sorumlu yazar/Corresponding author

e-posta: cgiriftinoglu@ eskisehir.edu.tr
} 
için de geleceğin en doğru şekilde tahmin edilmesi gerekmektedir.

Ülkemiz, coğrafi konumunun getirmiş olduğu üstünlük sayesinde hava taşımacılık sektöründe giderek artan hava trafiği sayısı ile önem kazanmaktadır. Hem transit uçuşlara imkan tanıyan coğrafi konumu hem de havayolu ulaşımına talebin en çok arttığı bölgeye yakın olması nedeniyle hava taşımacılık sektöründe göz önündedir. Dünyada 2016 yılındaki havalimanı yolcu trafiğine göre 11. sırada, Avrupa da ise 5. sırada yer almaktadır. Ayrıca Uluslararası Sivil Havacılık Teşkilatı'nın (ICAO-International Civil Aviation Organization) 2016 yıllık raporuna göre, dünyada, ücretli yolcu-kilometre siralamasında 10., ücretli ton-kilometre sıralamasında 11.,yük ton-kilometre sıralamasında ise 14. sırada yerini almaktadır. Havayolu Yolcu Taşıma Kapasitesi ile Küresel Rekabetçilik Raporu'na göre 138 ülke arasında da 16. siradadır.

Eurocontrol'ün 2018-2024 yılları için yapmış olduğu istatistiki çalışmada, Avrupa'daki uçuş operasyon sayısının yıllık \% 2,3 oranında büyümesi tahmin edilmektedir. Aynı çalışmada, Türkiye'nin uçuş operasyon sayısının 2017 y1lına kıyasla, kısa vadede ortalama \% 6 oranında, orta vadede ise yaklaşık \% 4,9 oranında yıllık büyüme göstermesi beklenmektedir. Hava taşımacılığı açısından öneme sahip olan ülkemizin, iç hat, diş hat ve toplam olmak üzere yolcu, uçak ve yük sayısına ilişkin doğru tahminlemenin yapılması ve böylece gelecek için öngörünün sağlanması önem kazanmaktadır. Yapılan çalışmalar incelendiğinde, birçok farklı tahmin yönteminin kullanıldığı görülmektedir.

Önder ve Hasgül (2009), klasik zaman serisi analizinden Box-Jenkins modeli ile yapay sinir ağları tahmin yöntemlerini kullanarak 2008-2010 yılları için Türkiye'ye gelen yabancı turist sayısı için bir araştırma yapmıştır. Aylık zaman serisi verileri dikkate alındığında, Winter'ın mevsimsel üstel düzeltme tekniği ile yapay sinir ağları yönteminin iki başarılı tahmin yöntemi olduğunu ortaya koymuşlardır.

Phyoe ve ark. (2016), Singapur uçuş bilgi bölgesi için 2015 yılına ait verileri kullanarak üç farklı tahmin yöntemi; üstel trend, ARIMA ve ARIMAX ile gelecek 15 y1l için beklenen hava trafik sayısını öngörmüş ve elde edilen sonuçları karşılaştırmıştır.

Dantas ve ark. (2016), hava taşımacılık endüstrisine daha doğru ve kesin talep tahmini elde etmek için Bagging (Bootstrap aggregating) ve Holt Winters yöntemlerini birleştirerek kullanmıştır. Önerilen yaklaşım 14 ülkeden alınan veriler üzerinde test edilmiş ve sonuçlar SARIMA, Holt Winters gibi toplam 5 yöntem ile ortalama mutlak yüzdelik hata kullanılarak karşılaştırılmıştır. Bagging Holt Winters yöntemi ile elde edilen sonuçların daha doğru olduğu sonucuna varılmıştır.

Nai ve ark (2017), Çin'deki artan hava trafiği için EMDSARIMA' ya dayalı bir tahmin modeli yaklaşımı önermiştir. Diğer kullanılan yaygın tahmin yöntemleri ile karşılaştırılmış ve önerilen model yaklaşımının avantajları kanıtlanmıştır.

Madhwal ve Avdeeva (2017) ise yaptıkları çalışmada, bölgesel yolcu trafiği ve gerekli uçak sayısını tahmin etmiştir. Elde edilen sonuçlar doğrultusunda, bölgesel olarak ihtiyaç duyulan uçak sayısı ile birlikte, havayolu şirketlerinin uçak filolarını oluştururken hangi uçak modellerinin (geniş, dar, küçük gövdeli) o bölgenin ihtiyacını karşılayabileceği yönünde tahminler yaparak öneriler getirmişlerdir.

Yumakoğulları ve ark. tarafindan Türkiye'deki havayolu yolcu ve kargo trafiğinin 11 yillık bir periyottaki büyümesi araştırılmıştır. Bu büyüme durumunda ihtiyaç duyulacak uçak sayısı, modelleri ve bu uçaklara hizmet verecek bakım onarım merkezlerinin kapasitesi ve bu merkezlerin çevre ülkelerle birlikte piyasa potansiyeli analiz edilmiştir.

Kuzu ve Yıldırım (2017) ise, Türkiye'de havayolu ulaşım talebinin tahmini üzerine yaptıkları çalışmada zaman seri analizi tekniklerinden Box-Jenkins ve gri tahmin yöntemlerini kullanılmıştır. Belirledikleri modeller ile elde edilen tahminleri, gözlenen değerler ile modellerinin sağlıklı tahminlerde bulunduğunu göstermişlerdir.

Havacılık sektöründe yolcu talebi tahmini için bir diğer çalışma da Efendigil ve Eminler (2017) tarafindan yapılmıştır. Çalışmada yapay zekâ teknikleri ile ekonometrik bir model olan regresyon tekniği karşılaştırılmıştır. Sonuçta, yolcu tahmini için en başarılı ve güvenilir sonuçları "yapay sinir ağları" tekniğinin verdiği bulunmuştur.

Yapılan çalışmalara bakıldığında, planlama ve kontrol işlemlerinde önemli bir araç olan tahminlemenin havacılık sektöründeki tartışılmaz önemi de vurgulanmaktadır. Tahminleme ya da diğer bir deyişle öngörü, gelecek ile ilgili belirsizliklerin aydınlanması, değerlendirilmesi açısından da kritik önem taşımaktadır. Bu çalışmada da, havayolu taşımacılığında önemi büyük olan ülkemizin iç hat, dış hat ve toplam olmak üzere uçak, yolcu ve yük sayılarının 2018-2023 yılları için eğri uydurma yöntemi kullanılarak tahmin edilmesi amaçlanmıştır. Çalışmada farklı eğri uydurma yöntemleri denenmiş ve uygulanabilirlikleri araştırılmıştır.

\section{Yöntem}

\subsection{Eğri Uydurma Yöntemi}

Mühendislik başta olmak üzere sosyal bilimler ve havacılık gibi birçok alanda iki değişken arasındaki ilişkiyi bulmaya yönelik problemler görülmektedir. Havacılıkta özellikle havayolu ulaşım talebi, yolcu, trafik, yük tahmini, meteorolojik şartların tahminlemesi ve bu durumdan etkilenen uçuş operasyon gecikmelerinin, yakıt tüketimi, emisyon ve maliyet tahminlemesi gibi bir çok çalışma yer almaktadır (Kuzu\&Yıldırım, 2016; Lee\&Zhong 2015, Qin\&Yu, 2015, Yong vd. 2017 ).

Eğri uydurma yöntemi, verilerin $\left(x_{i}, y_{i}\right), i=1, \cdots n$ şeklinde nokta çiftleri olarak elde edilmesi durumunda, bu değerler kullanılarak ortaya konan bir fonksiyona en yakın başka bir fonksiyonun belirlenmesi süreci olarak tanımlanır. Daha genel bir ifadeyle eğri uydurma yöntemi, herhangi iki değişken $\mathrm{x}$ ve $\mathrm{y}$ arasındaki ilişki ya da kuralın, verilen gözlem değerlerinden oluşan veri seti kullanılarak bulunmasıdır. Kısacası, iki değişken arasındaki ilişkinin cebirsel denklemlerle gösterilmesi anlamına gelir. Eğri uydurma için literatürde bulunan yöntemler, grafik yöntemi, grup ortalamaları yöntemi, momentler yöntemi ve 
en küçük kareler yöntemi olmak üzere dört başlık altında toplanabilir.

$\mathrm{Bu}$ çalışmada; bu dört yöntemden, tek bir çözüm kümesi veren ve sistematik bir prosedür olması nedeniyle de literatürde en çok yer alan yöntemlerden birisi olan En Küçük Kareler (EKK) Yöntemi'nin kullanılması amaçlanmıştır.

En küçük kareler yöntemini kısaca ifade edebilmek için Şekil 1 ile verilen grafiği ele alalım (Gangwar, 2015). Farz edelim, verilen $\left(x_{1}, y_{1}\right),\left(x_{2}, y_{2}\right), \cdots,\left(x_{n}, y_{n}\right)$ veri setine uydurulmak istenen eğri,

$$
y=a+b x+c x^{2}+\cdots+k x^{m}
$$

olsun. Aşağıdaki Şekil 1'de görüldüğü gibi herhangi bir $\left(x=x_{i}\right)$ 'deki gözlenmiş değerin ordinatı $y_{i}=P_{i} M_{i}$, buna karşılık fit edilen eğri üzerindeki uygun değer (beklenen ya da hesaplanan değer) ise $a+b x_{i}+c x_{i}^{2}+\cdots+$ $k x_{i}^{m}=L_{i} M_{i}$ 'dir. Dolayısıyla gözlemlenmiş değer ile beklenen değer arasındaki $P_{i} M_{i}-L_{i} M_{i}$ farkı $\left(x=x_{i}\right)$ 'deki hata olarak ifade edilir ve $e_{i}$ ile gösterilir.

Şekil 1. En Küçük Kareler Prensibi

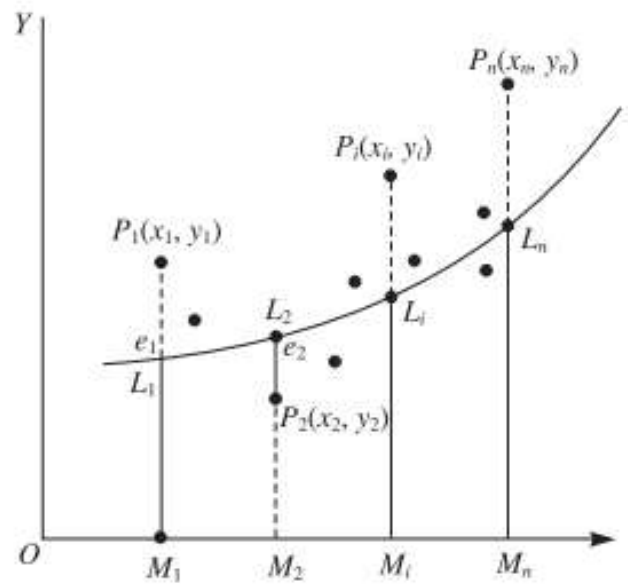

Açıkça görülmektedir ki bu hataların bazıları pozitif, bazıları ise negatif değer alacaklardır. Dolayısıyla toplam hatadan söz edebilmek için her birinin karesi alınarak hata kareler toplamı yani $S=e_{1}^{2}+e_{1}^{2}+\cdots+e_{n}^{2}$ dikkate alınır. $\mathrm{Bu}$ durumda veriyle en iyi uyuşan eğri, $e_{i}$ (hatalar) 'leri mümkün olduğunca küçük olan, bir başka değişle hataların kareleri toplamı $S$ 'i minumum yapan eğridir. Hata kereler toplamını minimize etmeyi amaçlayan bu yöntem, "en küçük kareler yöntemi” olarak bilinir.

$\mathrm{Bu}$ çalışmada, Devlet Hava Meydanları İşletmesi'nin (DHMI) Türkiye geneli havalimanları için yayımladığı istatistiklerden yararlanarak elde edilmiş hava taşımacılığ verileri kullanılmıştır. Bu veri seti; 2002-2017 yıllarına ait, iç hat, dış hat ve toplam olmak üzere uçak, yolcu ve yük trafiğinden oluşmaktadır (Tablo 1, Tablo 2 ve Tablo 3 ). Mevcut veriler incelendiğinde, zaman serisinin bir trend bileşenine sahip olduğu açık bir şekilde görülmektedir. $\mathrm{Bu}$ nedenle lineer, karesel, kübik, üstel vb. birçok eğri tahmin modelleri kullanılmıştır. Dolayısıyla da alt bölümde bu çalışmada kullanılan tüm modeller ve bunlardan bir kaçı için en küçük kareler yöntemi ile gerçekleştirilen eğri uydurma prosedürü gösterilecektir.
Tablo 1. İç Hat, Dış Hat ve Toplam Uçak Trafik Sayıları (20022017)

\begin{tabular}{llll}
\hline Yıl & Toplam & İc Hat & Dış Hat \\
\hline 2002 & 376579 & 157953 & 218626 \\
\hline 2003 & 374987 & 156582 & 218405 \\
\hline 2004 & 449493 & 196207 & 253286 \\
\hline 2005 & 551980 & 265113 & 286867 \\
\hline 2006 & 627401 & 341262 & 286139 \\
\hline 2007 & 688468 & 365177 & 323291 \\
\hline 2008 & 741765 & 385764 & 356001 \\
\hline 2009 & 788469 & 419422 & 369047 \\
\hline 2010 & 919411 & 497862 & 421549 \\
\hline 2011 & 1042369 & 579488 & 462881 \\
\hline 2012 & 1093047 & 600818 & 492229 \\
\hline 2013 & 1223795 & 682685 & 541110 \\
\hline 2014 & 1345954 & 754259 & 591695 \\
\hline 2015 & 1456673 & 832958 & 623715 \\
\hline 2016 & 1452995 & 886228 & 566767 \\
\hline 2017 & 1535568 & 903617 & 629892 \\
\hline
\end{tabular}

Tablo 2. İç Hat, Dış Hat ve Toplam Yolcu Sayıları (2002-2017)

\begin{tabular}{llcc}
\hline Yıl & Toplam & İç Hat & Diş Hat \\
\hline 2002 & 33783892 & 8729279 & 25054613 \\
\hline 2003 & 34443655 & 9147439 & 25296216 \\
\hline 2004 & 45057371 & 14460864 & 30596507 \\
\hline 2005 & 55572426 & 20529469 & 35042957 \\
\hline 2006 & 61655659 & 28774857 & 32880802 \\
\hline 2007 & 70296532 & 31949341 & 38347191 \\
\hline 2008 & 79438289 & 35832776 & 43605513 \\
\hline 2009 & 85508508 & 41226959 & 44281549 \\
\hline 2010 & 102800392 & 50575426 & 52224966 \\
\hline 2011 & 117620469 & 58258324 & 59362145 \\
\hline 2012 & 130351620 & 64721316 & 65630304 \\
\hline 2013 & 149430421 & 76148526 & 73281895 \\
\hline 2014 & 165720234 & 85416166 & 80304068 \\
\hline 2015 & 181074531 & 97041210 & 84033321 \\
\hline 2016 & 173743537 & 102499358 & 71244179 \\
\hline 2017 & 190268438 & 105024785 & 85243652 \\
\hline
\end{tabular}

Tablo 3. İç Hat, Dış Hat ve Toplam Yük Trafik Sayıları (20022017)

\begin{tabular}{lllll}
\hline Yll & Toplam & İç Hat & Diş Hat \\
\hline 2002 & 896865 & 181262 & 715603 \\
\hline 2003 & 964080 & 188979 & 775101 \\
\hline 2004 & 1164349 & 26279 & 901559 \\
\hline 2005 & 1304241 & 324597 & 979644 \\
\hline 2006 & 1360550 & 389206 & 971344 \\
\hline 2007 & 1546184 & 414294 & 1131890 \\
\hline 2008 & 1644014 & 424555 & 1219459 \\
\hline 2009 & 1726345 & 484833 & 1241512 \\
\hline 2010 & 2021076 & 554710 & 1466366 \\
\hline 2011 & 2249473 & 617834 & 1631639 \\
\hline 2012 & 2249133 & 633076 & 1616057 \\
\hline 2013 & 2595317 & 744028 & 1851289 \\
\hline 2014 & 2893000 & 810858 & 2082142 \\
\hline 2015 & 3072831 & 871327 & 2201504 \\
\hline 2016 & 3076914 & 857335 & 2219579 \\
\hline 2017 & 3270670 & 922677 & 2347992 \\
\hline
\end{tabular}




\subsection{Lineer Model ve Eğri (Doğru) Uydurma} Prosedürü

$\left(x_{1}, y_{1}\right),\left(x_{2}, y_{2}\right), \cdots,\left(x_{n}, y_{n}\right)$ veri setine uydurulan lineer model

$$
y=a+b x
$$

şeklinde gösterilsin. Dolayısıyla $x_{1}$ değerine karşılık gelen teorik değer bir başka değişle tahmini değer $y_{\lambda_{1}}$ ile işaret edildiğinde gerçekleşen hata değeri $e_{1}=y_{1}-y_{\lambda_{1}}$ olacaktır. Böylece,

$$
\begin{aligned}
& e_{1}=y_{1}-\left(a+b x_{1}\right) \\
& e_{1}^{2}=\left(y_{1}-a-b x_{1}\right)^{2} \\
& \vdots \\
& e_{n}^{2}=\left(y_{n}-a-b x_{n}\right)^{2}
\end{aligned}
$$

olmak üzere, hata kareler toplamı $S$

$$
\begin{aligned}
S & =e_{1}^{2}+e_{1}^{2}+\cdots+e_{n}^{2} \\
S & =\sum_{i=1}^{n} e_{i}^{2} \\
S & =\sum_{i=1}^{n}\left(y_{i}-a-b x_{i}\right)^{2}
\end{aligned}
$$

şeklinde elde edilir. En küçük kareler prensibine göre de hata kareler toplamı olan $S$ 'nin minimizasyonunu sağlayan a ve b katsayılarını bulabilmek için,

$$
\begin{aligned}
& \frac{\partial S}{\partial a}=0 \\
& \frac{\partial S}{\partial b}=0
\end{aligned}
$$

(2) ve (3) eşitliklerinin çözümü ile

$$
\begin{aligned}
& \sum y=n a+\sum x \\
& \sum x y=a \sum x+b \sum x^{2}
\end{aligned}
$$

denklemleri elde edilir. (4) ve (5) denklemleri "normal denklemler" olarak ifade edilir ve bu denklemlerin çözümünden a ve b katsayılarına ulaşılmış olur. $\mathrm{Bu}$ katsayıları (1)'de yerine koyduğumuzda da veriye en iyi uyan doğru denklemi elde edilmiş olur.

\subsection{Karesel Model ve Eğri Uydurma Prosedürü}

$\left(x_{1}, y_{1}\right),\left(x_{2}, y_{2}\right), \cdots,\left(x_{n}, y_{n}\right)$ veri setine fit edilen (uydurulan) model,

$$
y=a+b x+c x^{2}
$$

şeklinde ikinci dereceden bir parabol ile gösterilsin. Dolayısıyla $x_{1}$ değerine karşılık gelen teorik değer bir başka değişle tahmini değer $y_{\lambda_{1}}$ ile işaret edildiğinde değeri $e_{1}=y_{1}-y_{\lambda_{1}}$ olacaktır. Böylece,

$$
\begin{aligned}
& e_{1}=y_{1}-\left(a+b x_{1}+c x_{1}^{2}\right) \\
& e_{1}^{2}=\left(y_{1}-a-b x_{1}-c x_{1}^{2}\right)^{2} \\
& \vdots \\
& e_{n}^{2}=\left(y_{n}-a-b x_{n}-c x_{n}^{2}\right)^{2}
\end{aligned}
$$

olmak üzere, hata kareler toplamı $S$

$$
\begin{gathered}
S=e_{1}^{2}+e_{1}^{2}+\cdots+e_{n}^{2} \\
S=\sum_{i=1}^{n} e_{i}^{2}
\end{gathered}
$$

$$
S=\sum_{i=1}^{n}\left(y_{i}-a-b x_{i}-c x_{i}^{2}\right)^{2}
$$

şeklinde elde edilir. En küçük kareler prensibine göre de hata kareler toplamı olan $S$ 'nin minimizasyonunu sağlayan a ve b katsayılarını bulabilmek için, $\frac{\partial S}{\partial a}=0, \frac{\partial S}{\partial b}=0$ ve , $\frac{\partial S}{\partial c}=0$ eşitliklerinin çözümü ile

$$
\begin{aligned}
& \sum y=n a+b \sum x+c \sum x^{2} \\
& \sum x y=a \sum x+b \sum x^{2} c \sum x^{3} \\
& \sum x^{2} y=a \sum x^{2}+b \sum x^{3} c \sum x^{4}
\end{aligned}
$$

denklemleri elde edilir. (7), (8) ve (9) denklemlerinin çözümünden a, b ve c katsayılarına ulaşılmış olur. Bu katsayıları (6)'da yerine koyduğumuzda da veriye en iyi uyan parabol denklemi elde edilmiş olur.2.4. Üstel Model ve Eğri Uydurma Prosedürü

Veriye fit edilmek istenen üstel model

$$
y=a e^{b x}
$$

şeklinde olsun. Her iki tarafın logaritmasını almak suretiyle,

$$
\begin{aligned}
& \log _{10} y=\log _{10} a+b x \log _{10} e \\
& Y=A+B x
\end{aligned}
$$

şeklinde lineer modele dönüşmüş olur. Burada $Y=\log _{10} y$ , $A=\log _{10} a$ ve $B=b \log _{10} e$ 'dir. Böylece (10) denklemi için normal denklemler,

$$
\begin{aligned}
& \sum Y=n A+\sum x \\
& \sum x Y=A \sum x+B \sum x^{2}
\end{aligned}
$$

şeklinde olur ve bu iki denklemin çözümünden elde edilen $A$ ve $B$ değerlerinden,

$$
a=\operatorname{antilog} A \quad \text { ve } b=\frac{B}{\log _{10} e}
$$

katsayılarına ulaşılır (Gangwar, 2015).

Çalışmada kullanılan modeller Lineer, Karesel ve Üstel modellerle sınırlı kalmayıp, söz konusu veriye aşağıdaki modeller de uydurulmuştur.

$$
\begin{array}{ll}
\text { Logaritmik } & Y=a+b \ln x \\
\text { Kübik } & Y=a+b x+c x^{2}+d x^{3} \\
\text { Ters } & Y=a+b / x \\
\text { Birleşik } & Y=a b^{x} \\
\text { Kuvvet } & Y=a x^{b} \\
\text { S } & Y=\exp (a+b / x) \\
\text { Büyüme } & Y=\exp \left(a+b^{x}\right)
\end{array}
$$

Çalışmada fit edilen 10 model arasında seçim yapabilmek, bir başka değişle öngörü yeteneklerini karşılaştırabilmek için model seçim kriterlerinden Hata Kareler Ortalaması (Mean Squared Error, MSE) ve Ortalama Mutlak Yüzdelik Hata (Mean Absolute Percentage Error, MAPE) kullanılmıştır. Bu iki seçim kriteri, literatürde en çok kullanılanlardan olup, MSE ölçeğe bağlı iken MAPE değeri ölçekten bağımsızdır. 
Ortalama Karesel Hata:

$$
M S E=\frac{1}{n} \sum_{i=1}^{n} e_{i}^{2}=\frac{S}{n}
$$

Ortalama Mutlak Yüzdelik Hata ise $p_{i}=\frac{\left|e_{i}\right|}{y_{i}}$ olmak üzere,

$$
M A P E=\frac{1}{n} \sum_{i=1}^{n} 100 . p_{i}
$$

şeklinde hesaplanır.

Veriye uyan 10 farklı eğriden en düşük MAPE ya da MSE değerine sahip eğri seçilerek, ileriye dönük tahmin yapılır.

\section{Bulgular ve Yorumlar}

$\mathrm{Bu}$ çalışmada Devlet Hava Meydanları İşletmesi'nin Türkiye geneli havalimanları için yayımladığı istatistiklerden yararlanarak elde edilmiş hava taşımacılığ verileri kullanılmıştır. Bu veri seti; 2002-2017 yıllarına ait, iç hat, dış hat ve toplam olmak üzere uçak, yolcu ve yük trafiğinden oluşmaktadır. Toplam uçak, yolcu ve yük sayısında transit uçuş, yolcu ve yük sayıları dahil edilmemiştir.

Çalışmada, eğri uydurmak bir başka deyişle 10 farklı modeli tahmin etmek, onlara uygun MSE ve MAPE değerlerini hesaplamak ve grafiklerini çizdirmek için Mathematica V11.3'te program yazılmıştır.

2018-2023 y1lların ait uçak trafik, yolcu trafik ve yük trafik sayılarına ait elde edilen tahminler Tablo 4, Tablo 5 ve

\begin{tabular}{|c|c|c|c|c|}
\hline $\begin{array}{l}\text { Tablo 4. } \\
\text { Toplam, İç } \\
\text { Hat, Dış } \\
\text { Hat Uçak } \\
\text { Trafik } \\
\text { Tahminleri } \\
(2018- \\
2023)\end{array}$ & & Toplam & İç Hat & Dış Hat \\
\hline $\begin{array}{l}\text { Ĕgri Tahmin } \\
\text { Modeli }\end{array}$ & & Kübik & Kübik & Karesel \\
\hline & 2018 & 1580999 & 995921 & 656290 \\
\hline & 2019 & 1618052 & 1057174 & 684416 \\
\hline & 2020 & 1639166 & 1117292 & 712437 \\
\hline & 2021 & 1642440 & 1175926 & 740353 \\
\hline & 2022 & 1625967 & 1232727 & 768165 \\
\hline & 2023 & 1587844 & 1287347 & 795872 \\
\hline
\end{tabular}
Tablo 6'da toplam, iç hat ve dış hat olmak üzere verilmiştir.

Ayrıca uçak, yolcu ve yük trafiğgi için eğri tahmin modelleri, katsayıları ve model seçim kriterleri değerleri Ek 1, Ek 2 ve Ek 3'te detaylı şekilde gösterilmektedir. Model seçim kriterlerinden MAPE ve MSE'si en düşük değere sahip olan modellerin seçilmesiyle, belirlenen eğriye uygun öngörü değerleri elde edilmiştir. Söz konusu 9 değişken için veriyle uyuşan 10 farklı eğriden, genellikle veriye en iyi uyan eğri kübik ve karesel modeller olmuştur. En iyi uyan bu eğri grafikleri ise Şekil 2 (a,b,c,d), Şekil 3 (a,b,c,d) ve Şekil 4 (a,b,c)'te verilmiştir.
Şekil 2a. Toplam Uçak Trafiği (Kübik) Tahmini

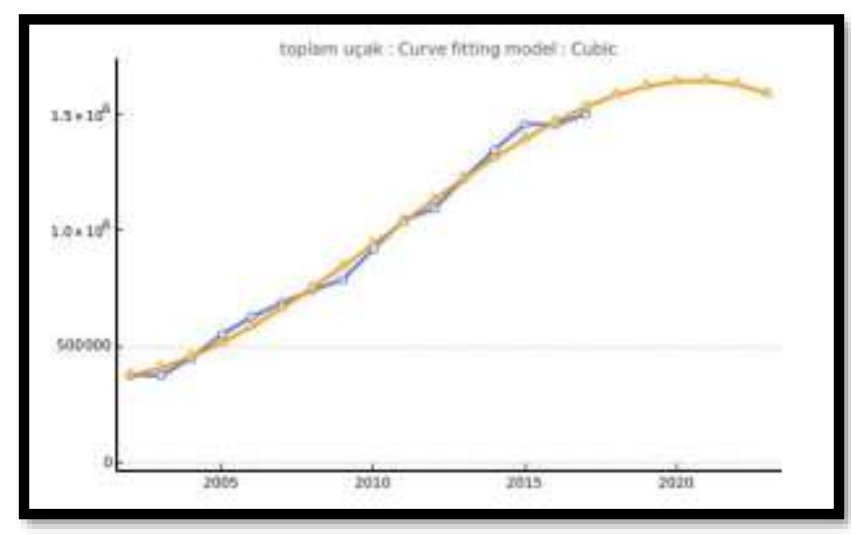

Şekil 2b. İç Hat Uçak Trafiği (Kübik) Tahmini

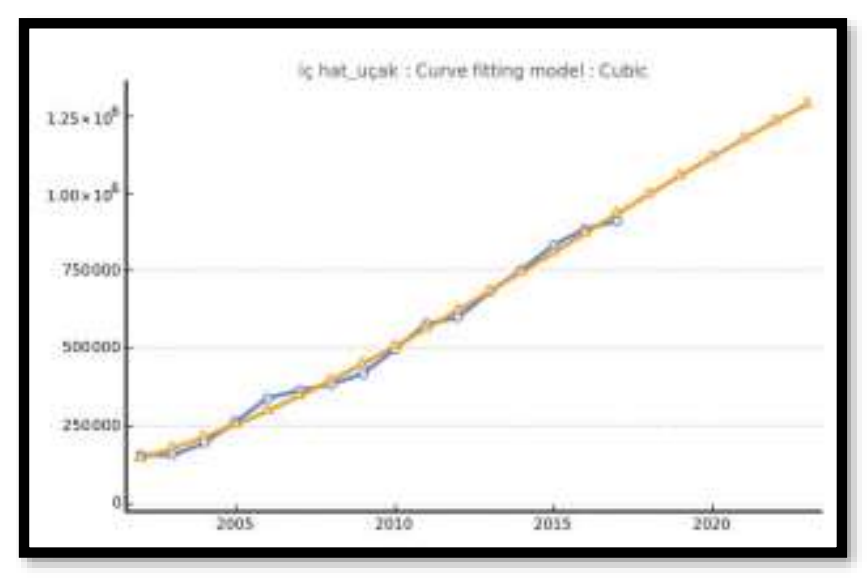

Toplam uçak ve iç hat uçak trafiği değişkenleri için uydurulan 10 eğriden en küçük MSE ve MAPE değerlerine sahip eğriler kübik olmuştur.

Şekil 2c. Dış Hat Uçak Trafiği (Kübik) Tahmini

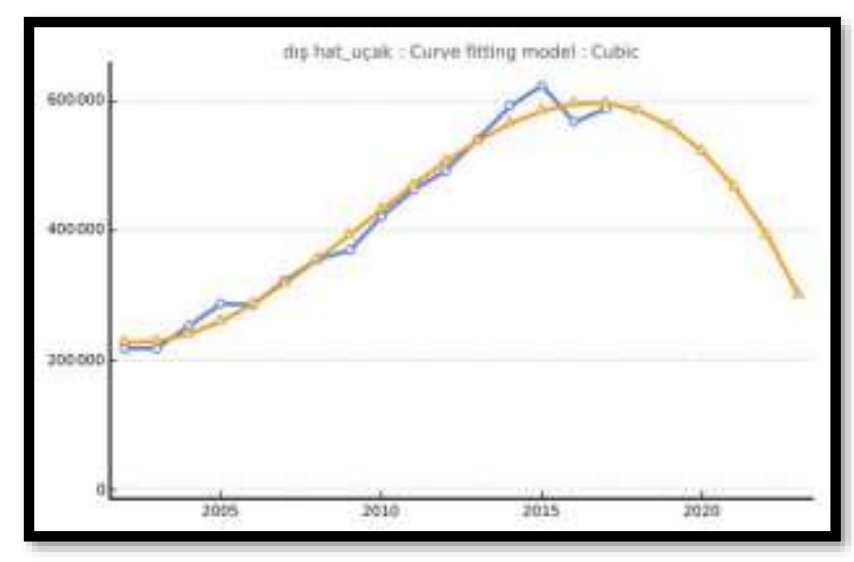

Dış hat uçak trafiği için kübik formunun MAPE değerinin düşük olmasına rağmen 2018-2023 öngörü değerlerinin giderek azalacağı görülmüştür (Şekil 2c). Bu nedenle, kübikten sonra en düşük MAPE ve MSE değerine sahip karesel eğrinin öngörü değerlerinin kullanılmasının daha uygun olacağına karar verilmiştir (Şekil 2d). 
Şekil 2d. Diş Hat Uçak Trafiği (Karesel) Tahmini

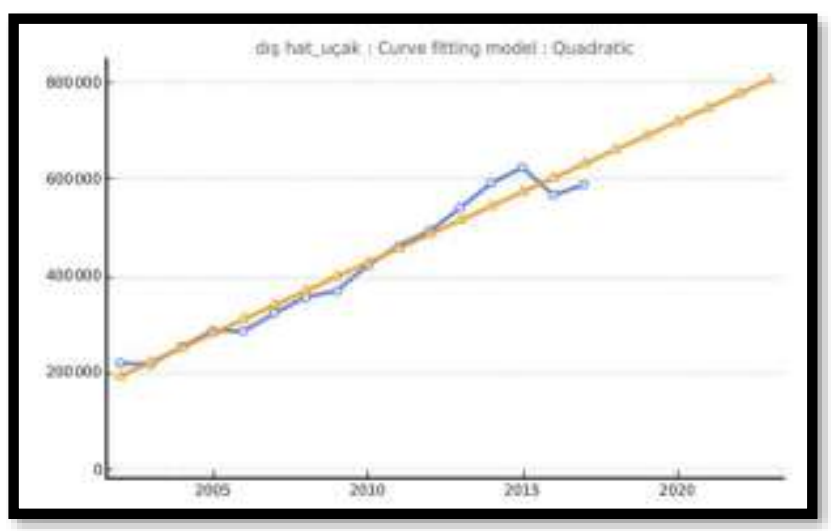

Tablo 5. Toplam, İç Hat, Dış Hat Yolcu Trafik Tahminleri (20182023)

\begin{tabular}{cccc}
\hline \multicolumn{1}{c}{$\begin{array}{c}\text { Ĕgri Tahmin } \\
\text { Modeli }\end{array}$} & Toplam & İç Hat & Diş Hat \\
\hline 2018 & 201732848 & 121240813 & 91736810 \\
\cline { 2 - 4 } 2019 & 208392218 & 130745930 & 96828549 \\
\cline { 2 - 4 } 2020 & 212945870 & 140265254 & 102005224 \\
\cline { 2 - 4 } 2021 & 215116267 & 149753336 & 107266832 \\
\hline 2022 & 214625867 & 159164725 & 112613375 \\
\hline 2023 & 211197133 & 168453974 & 118044853 \\
\hline
\end{tabular}

Şekil 3a. Toplam Yolcu Trafiği (Kübik) Tahmini

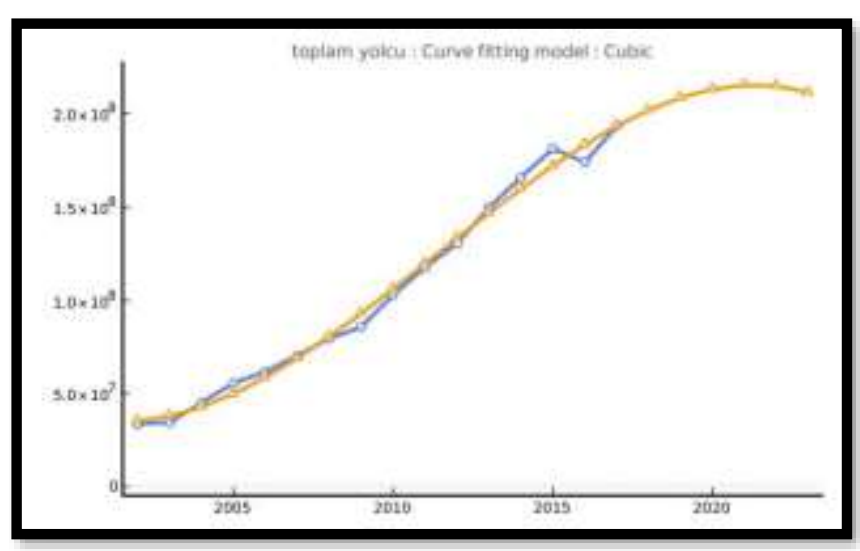

Şekil 3b. İç Hat Yolcu Trafiği (Kübik) Tahmini

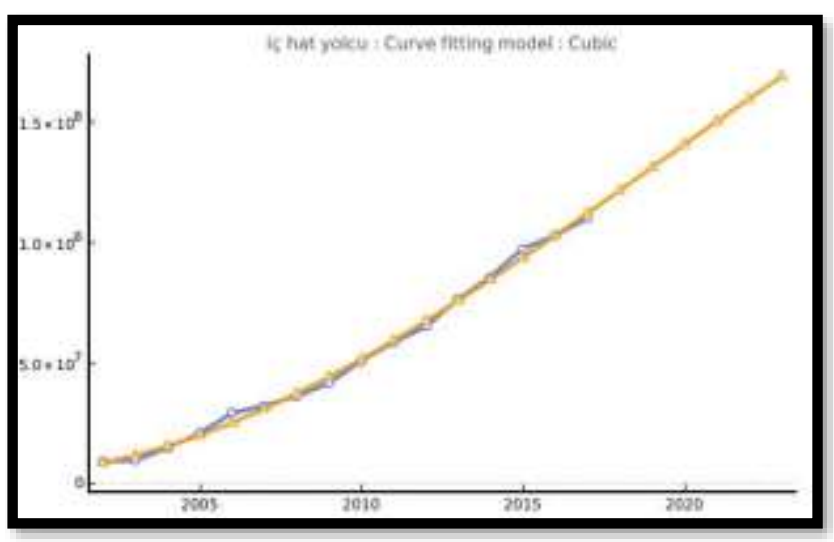

Toplam yolcu ve iç hat yolcu trafiği değişkenleri için uydurulan 10 eğriden en küçük MSE ve MAPE değerlerine sahip eğriler kübik olmuştur (Şekil 3a ve Şekil 3b).

Şekil 3c. Dış Hat Yolcu Trafiği (Kübik) Tahmini
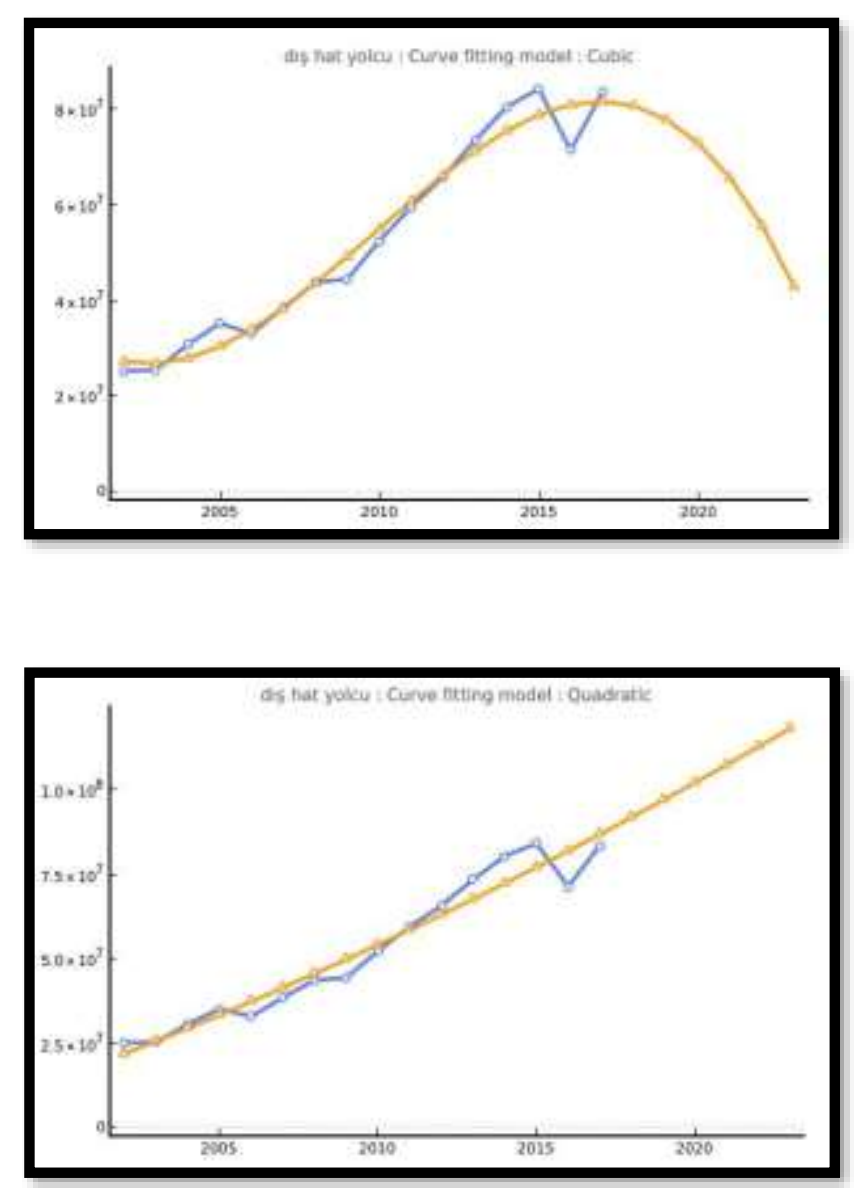

Şekil 3d. Dış Hat Yolcu Trafiği (Karesel) Tahmini

Görüldüğü gibi dış hat uçak trafiği ile aynı durum dış hat yolcu trafiği için de geçerli olmuş, kübik eğrinin MSE ve MAPE değerleri daha düşük olmasına rağmen, karesel eğrinin daha iyi uyduğu gözlenmiştir. Söz konusu seçilen kübik ve karesel modellerle yapılan tahminler Şekil 3c ve Şekil 3d ile gösterilmiştir.

Tablo 6. Toplam, İç Hat, Dış Hat Yük Trafik Tahminleri (20182023)

\begin{tabular}{|c|c|c|c|}
\hline \multirow{2}{*}{$\begin{array}{l}\text { Ĕgri Tahmin } \\
\text { Modeli }\end{array}$} & Toplam & İç Hat & Diş Hat \\
\hline & Karesel & Kübik & Karesel \\
\hline 2018 & 3648461 & 947445 & 2665622 \\
\hline 2019 & 3890617 & 976653 & 2853589 \\
\hline 2020 & 4140994 & 999282 & 3049413 \\
\hline 2021 & 4399590 & 1014604 & 3253096 \\
\hline 2022 & 4666407 & 1021886 & 3464638 \\
\hline 2023 & 4941445 & 1020399 & 3684038 \\
\hline
\end{tabular}

Şekil 4a, Şekil 4b ve Şekil 4c de ise, toplam, iç ve dış hat yük trafiği değişkenleri için 10 eğriden veriye en iyi uyan, en küçük MSE ve MAPE değerlerine sahip eğriler gösterilmiştir. 
Şekil 4a. Toplam Yük Trafiği (Karesel) Tahmini

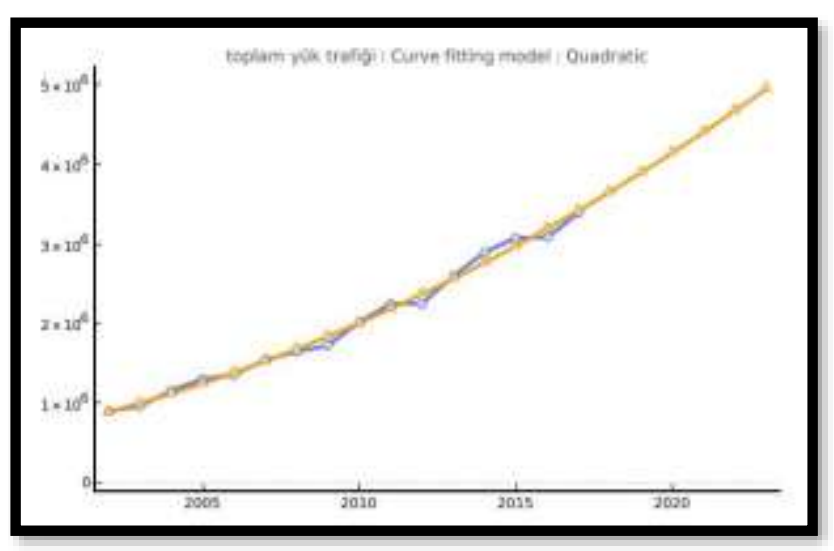

Şekil 4b. İç Hat Yük Trafiği (Kübik) Tahmini

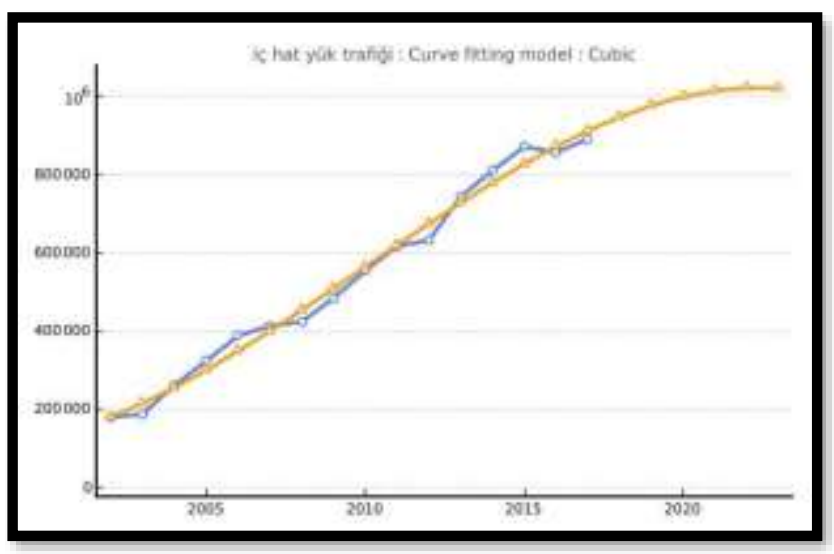

Şekil 4c. Dış Hat Yük Trafiği (Karesel) Tahmini

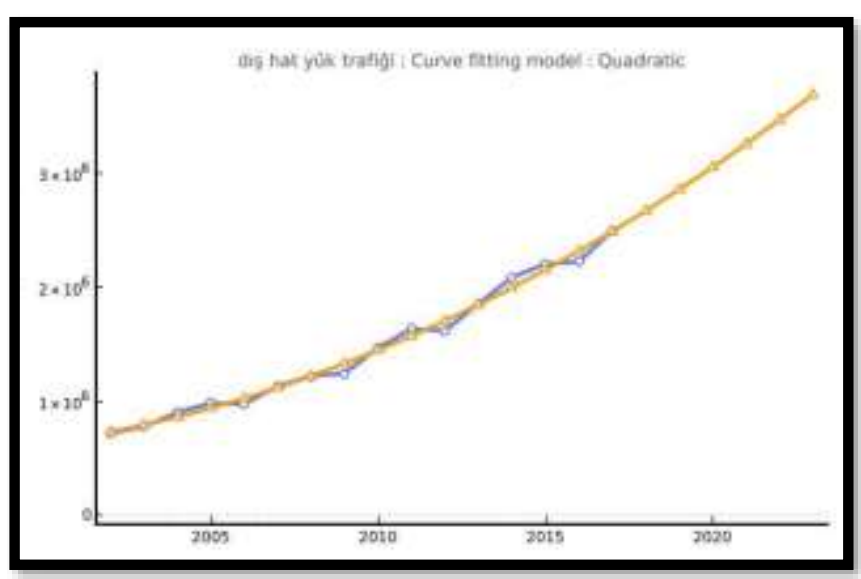

Tablo 7'de DHMI'nin 2019 ve 2020 yılları için yapmış olduğu tahminler ile bu çalışma sonucunda elde edilen tahminler karşılaştırılmıştır. Çalışmada elde edilen değerlerin DHMI'nin yapmış olduğu tahmini değerlere yakınlık gösterdiği gözlenmiştir. Çalışmada 2019 yılı için elde edilen tahminler, DHMI'nin tahminlerine göre toplam uçak trafiği için \% 4, toplam yolcu trafiği için \%10,6 ve toplam yük trafiği için \%1,21 fark göstermektedir. 2020 yılı için ise, \% 6, \% 13,5 ve \% 0,2 sırasıyla toplam uçak, yolcu ve yük trafiği için gözlenen farklardır. Ayrıca iç hat ve dış hat uçak, yolcu ve yük trafikleri için fark değerleri Tablo 4 'te verilmiştir. DHMI istatistiklerinde sadece 2019 ve 2020 yılı tahminlerinin bulunması nedeniyle karşılaştırma bu yıllar için yapılmıştır. Çalışma sonuçlarının, DHMİ'nin tahminleri ile yakınlık göstermesi, çalışmanın doğruluk ve geçerliliğinin pekiştirilmesi açısından önem kazanmıştır.

Tablo 4. 2019 ve 2020 Yılları için DHMİ Tahminleri ile Çalışma Tahminlerinin Karşılaştırılması

\begin{tabular}{|c|c|c|c|c|}
\hline & $2019 / 2020$ & DHMİ & $\begin{array}{c}\text { EĞRİ } \\
\text { UYDURMA } \\
\end{array}$ & $\begin{array}{c}\text { FARK } \\
(\%)\end{array}$ \\
\hline \multirow{6}{*}{ 光范 } & \multirow{2}{*}{ Toplam } & $1.692,689$ & $1.618,052$ & 4,41 \\
\hline & & $1.746,535$ & $1.639,166$ & 6,15 \\
\hline & \multirow{2}{*}{ İç Hat } & $1.010,899$ & $1.057,174$ & $-4,58$ \\
\hline & & $1.068,864$ & $1.117,292$ & $-4,53$ \\
\hline & \multirow{2}{*}{ Diş Hat } & 671.790 & 684.416 & $-1,88$ \\
\hline & & 677.671 & 712.437 & $-5,13$ \\
\hline \multirow{6}{*}{ 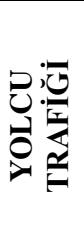 } & \multirow[b]{2}{*}{ Toplam } & $233.161,291$ & $208.392,218$ & 10,62 \\
\hline & & $246.324,478$ & $212.945,870$ & 13,55 \\
\hline & \multirow{2}{*}{ İç Hat } & $129.599,780$ & $130.745,930$ & $-0,88$ \\
\hline & & $138.644,216$ & $140.265,254$ & $-1,17$ \\
\hline & \multirow{2}{*}{ Dış Hat } & $103.561,511$ & $968.285,49$ & 6,50 \\
\hline & & $107.680,262$ & $102.005,224$ & 5,27 \\
\hline \multirow{6}{*}{ 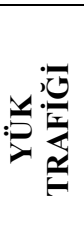 } & \multirow[b]{2}{*}{ Toplam } & $3.938,355$ & $3.890,617$ & 1,21 \\
\hline & & $4.149,730$ & $4.140,994$ & 0,21 \\
\hline & \multirow{2}{*}{ İç Hat } & $1.088,418$ & 976.653 & 10,27 \\
\hline & & $1.161,130$ & 999.282 & 13,94 \\
\hline & \multirow{2}{*}{ Dış Hat } & $2.849,937$ & $2.853,589$ & $-0,13$ \\
\hline & & $2.988,601$ & $3.049,413$ & $-2,03$ \\
\hline
\end{tabular}

\section{Sonuç ve Öneriler}

Bu çalışmada DHMI'nin 2002-2017 yıllarına ait, iç hat, dış hat ve toplam olmak üzere uçak, yolcu ve yük trafiği için yayımladığı veriler kullanılmıştır. Çalışmada eğri uydurma yöntemi uygulanmıştır. 10 farklı modeli tahmin etmek, onlara uygun MSE ve MAPE değerlerini hesaplamak ve grafiklerini çizdirmek için Mathematica V11.3'te program yazılmıştır.

Çalışmada toplam uçak trafiğinde 2019 yılı için \%2,34; 2020 yılında \%1,30; 2021 yılında ise \%0,2 oranında artış görülmesi beklenirken; 2022 ve 2023 yıllarında bir önceki yıllara göre ortalama \% 1,5 oranında azalma olacağı tahmin edilmiştir. Toplam yolcu sayısında ise 2019 yılında \%3,3, 2020 yılında $\% 2,18 ; 2021$ yılında $\% 1$ oranında artış olması beklenirken; 2022 yılında \%0,2 ve 2023 yılında \%1,6 oranında azalma öngörülmüştür. Toplam yük trafiğinin ise son beş yıl içinde ortalama \%6 oranında artış göstermesi beklenmektedir.

Literatür taramasında Kuzu\&Yıldırım (2017) ve Efendigil\&Eminler (2017)'in aynı veri setini kullanarak yaptıkları çalışmalar görülmektedir.

Kuzu\&Yıldırım 'ın çalışmasında Box Jenkins modelleri ile gri tahminleme yöntemleri kullanılmış ve sadece 2017 yılına ait öngörü yapılmıştır. Efendigil\&Eminler ise, 2015 yılına kadar olan verileri kullanarak yapay sinir ağları tekniği ile elde edilen RMSE değerinin diğer tekniklere göre daha düşük değer verdiğini göstermiştir.

$\mathrm{Bu}$ çalışmada ise, aynı veri setini kullanan diğer iki çalışmadan farklı olarak 2019-2020 yıllarına ait öngörüler yapılmış ve DHMI'nin öngörüleri ile karşılaştırılmıştır. 
Çalışmada 2019 yılı için elde edilen tahminler, DHMİ'nin tahminlerine göre toplam uçak trafiği için \% 4, toplam yolcu trafiği için $\% 10,6$ ve toplam yük trafiği için $\% 1,21$ fark göstermektedir. 2020 yılı için ise, \% 6, \% 13,5 ve \% 0,2 sırasıyla toplam uçak, yolcu ve yük trafiği için gözlenen farklardır. Çalışma sonuçlarının, DHMI'nin tahminleri ile yakınlık göstermesi, çalışmanın doğruluk ve geçerliliğinin pekiştirilmesi açısından önem kazanmaktadır.

\section{Kaynakça}

Dantas, TM., Oliveria FLC., \& Rpolho HMV. (2017). Air transportation demand forecast through Bagging Holt Winters methods. Journal of Air Transport Management, (59), 116-123.

Devlet Hava Meydanları İşletmesi Resmi websitesi, (Erişim: 10.07.2018), http://www.dhmi.gov.tr/istatistik.aspx

Efendigil, T., \& Eminler, Ö.M. (2017). Havacılık sektöründe talep tahmininin önemi: yolcu talebi üzerine bir tahmin modeli. Tarım ve Gida Değer Zincirlerinde Yöneylem Araştırmalarl ve Endüstri Mühendisliği Özel Sayısı, 12 (özel sayı), 14-30.

Eurocontrol Seven Year Forecast (2018-2024), Flight Movements and Service Units. (Erişim: 22.07.2018), https://www.eurocontrol.int/sites/default/files/content/d ocuments/official-documents/forecasts/seven-yearflights-service-units-forecast-2018-2024-Feb2018.pdf

Gangwar H.S. (2015). Textbook of Engineering Mathematics-III.(Erişim:25.06.2018), https://www.newagepublishers.com/samplechapter/0019 38.pdf

International Civil Aviation Organization (2006). Manual on Air Traffic Forecasting- Doc. 8991, Third Edition.

Kuzu, S., \& Yıldırım, B.F., (2017). Box-Jenkins ve gri tahmin yöntemleri ile Türkiye'de hava yolu ulaşım talebinin tahmini. Söke İşletme Fakültesi Priene Uluslararası Sosyal Bilimler Dergisi, 1(2), 36-49.

Lee, Y. X. \& Zhong, Z.W. (2016). A study of the relationship between adverse weather conditions and flight delay. Journal of Advances in Technology and Engineering Research, 2(4), 113-117.

Madhwal Y., \& Avdeeva Z. (2017). Planning in aircraft industry based on prediction of air traffic. Procedia Computer Science, (122), 1047-1054.

Murphy, C.M., Miller, B., and Sherry, L. (2015). Effects of Fuel Price on Total Fuel Burn and System Capacity- An Analysis of Advanced Engine and Airframe Technology and Airline Responses to Changes in Fuel Price, 5th AIAA Aviation Technology, Integration, and Operations Conference.

Nai, W., Liu, L., Wang S., \& Dong, D. (2017). An EMDSARIMA-Based Modeling Approach for Air Traffic
Forecasting, Algorithms, 10 (4), 139. doi:10.3390/a10040139

Önder, E., \& Hasgül, Ö. (2009). Yabancı ziyaretçi sayısının tahmininde box jenkins modeli, winters yöntemi ve yapay sinir ağlarıyla zaman serisi analizi. Istanbul Üniversitesi Işletme İktisadi Enstitüsü Yönetim Dergisi, 20(62), 62-83.

Önder E., \& Kuzu, S. (2014). Forecasting air traffic volumes using smoothing techniques, Journal of Aeronautics and Space Technologies, 7(1), 65-85.

Phyoe, SM., Guo R., \& Zhong ZW. (2016). An air traffic forecasting study and simulation, International Journal of Science and Technology, 2(3), 55-69.

Qin, Q., \& Yu, H. (2015). A Statistic Analysis of Flight Delays of Major US Airports: Illustrated by the Example of the JFK Airport, Proceedings of 4th International Conference on Logistics, Informatics and Service Science, 469-474.

Tong, L.,Ying, C., \& Qian, W. (2017). A Curve Fitting Method for Evaluating Pilot Operation Quality. International Conference on Mechatronics and Intelligent Robotics, (2), 93-101.

Ulaşan ve Erişen Türkiye (2017). Havacılık ve Uzay Teknolojileri.(Erişim:06.06.2012), http://www.udhb.gov.tr/images/faaliyet/a5ec26a31a722 81.pdf

Yumakoğulları, Ö., Aydemir R., \& Güloğlu, B. (2015). The development of turkish air traffic fleet and mro market, KOSBED, (30), $31-50$. 
Ek 1. Uçak Trafiği İçin Eğri Tahmin Modelleri, Katsayıları ve Model Seçim Kriter Değerleri

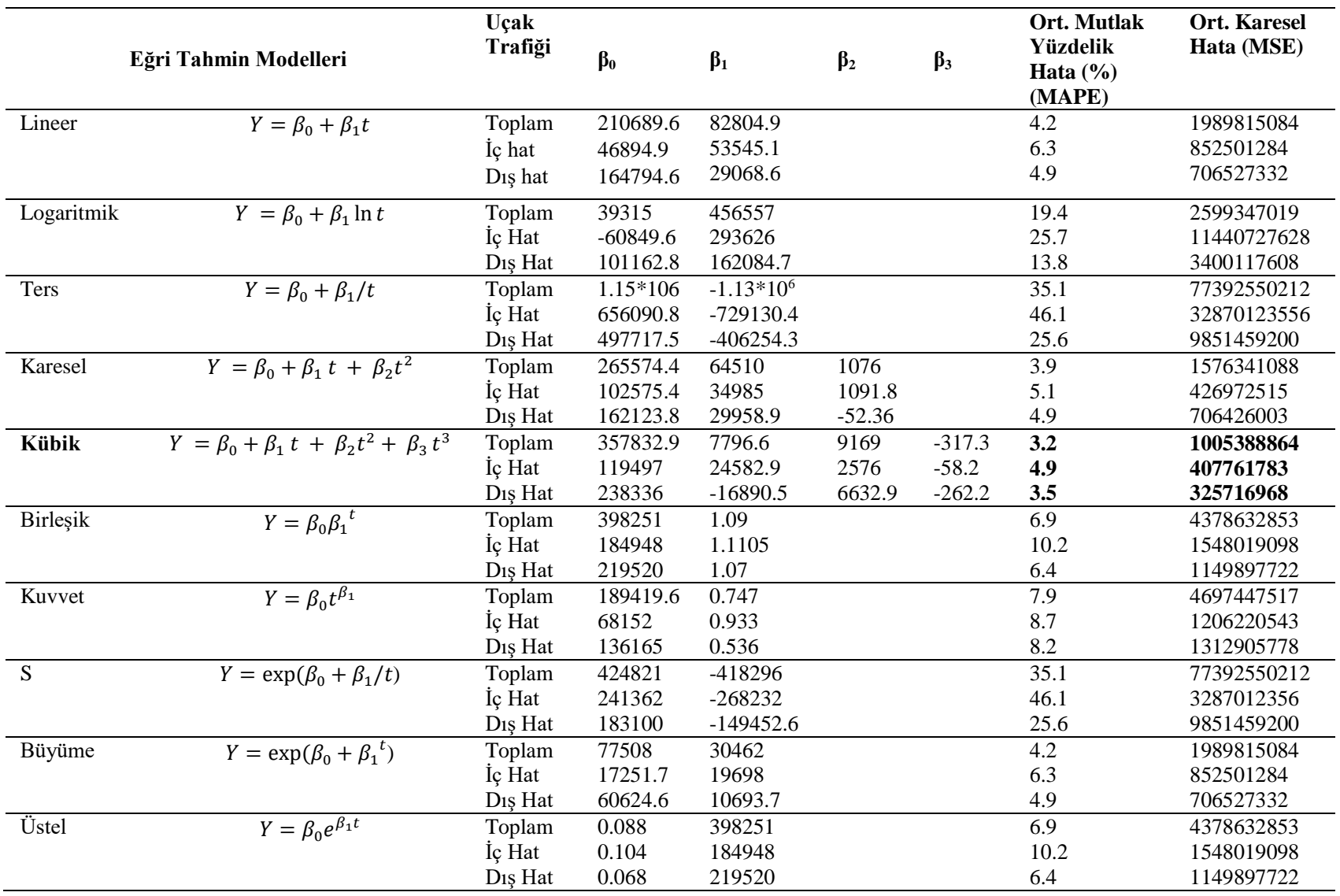

Ek 2. Yolcu Trafiği İçin Eğri Tahmin Modelleri, Katsayıları ve Model Seçim Kriter Değerleri

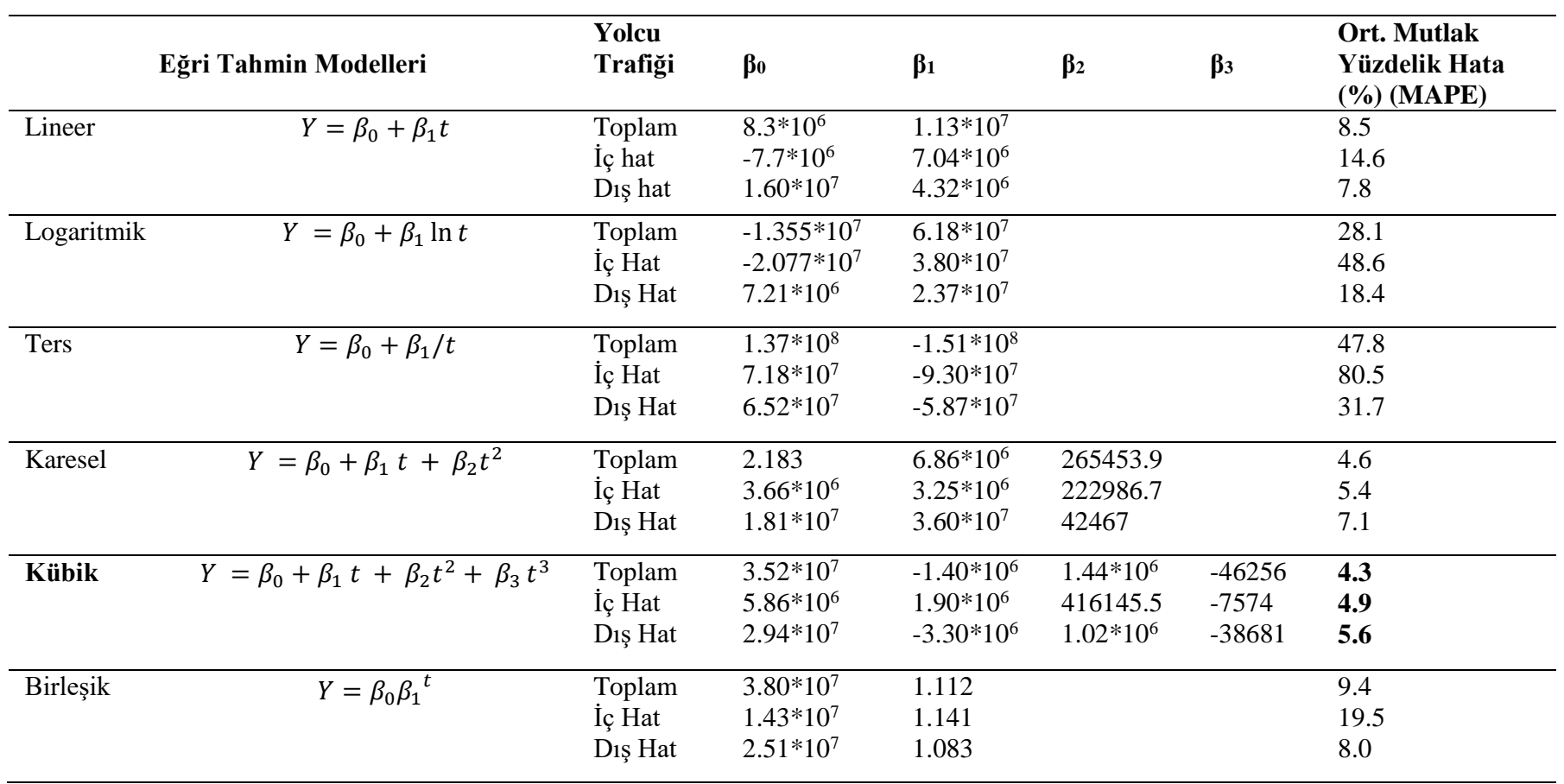




\begin{tabular}{|c|c|c|c|c|c|}
\hline Kuvvet & $Y=\beta_{0} t^{\beta_{1}}$ & $\begin{array}{l}\text { Toplam } \\
\text { İç Hat } \\
\text { Diş Hat }\end{array}$ & $\begin{array}{l}1.32 * 10^{7} \\
3.077 * 10^{6} \\
1.336 * 10^{7}\end{array}$ & $\begin{array}{l}0.963 \\
1.291 \\
0.657\end{array}$ & $\begin{array}{l}10.8 \\
9.7 \\
11.7\end{array}$ \\
\hline Büyüme & $Y=\exp \left(\beta_{0}+\beta_{1}{ }^{t}\right)$ & $\begin{array}{l}\text { Toplam } \\
\text { İç Hat } \\
\text { Diş Hat }\end{array}$ & $\begin{array}{l}3.05 * 10^{6} \\
-2.83 * 10^{6} \\
5.88 * 10^{6}\end{array}$ & $\begin{array}{l}4.18 * 10^{6} \\
2.59 * 10^{6} \\
1.59 * 10^{6}\end{array}$ & $\begin{array}{l}8.5 \\
14.6 \\
7.8\end{array}$ \\
\hline Üstel & $Y=\beta_{0} e^{\beta_{1} t}$ & $\begin{array}{l}\text { Toplam } \\
\text { İç Hat } \\
\text { Diş Hat }\end{array}$ & $\begin{array}{l}0.106 \\
0.132 \\
0.080 \\
\end{array}$ & $\begin{array}{l}3.80 * 10^{7} \\
1.43 * 10^{7} \\
2.50 * 10^{7}\end{array}$ & $\begin{array}{l}9.4 \\
19.5 \\
8.0 \\
\end{array}$ \\
\hline
\end{tabular}

Ek 3. Yük Trafiği İçin Eğri Tahmin Modelleri, Katsayıları ve Model Seçim Kriter Değerleri

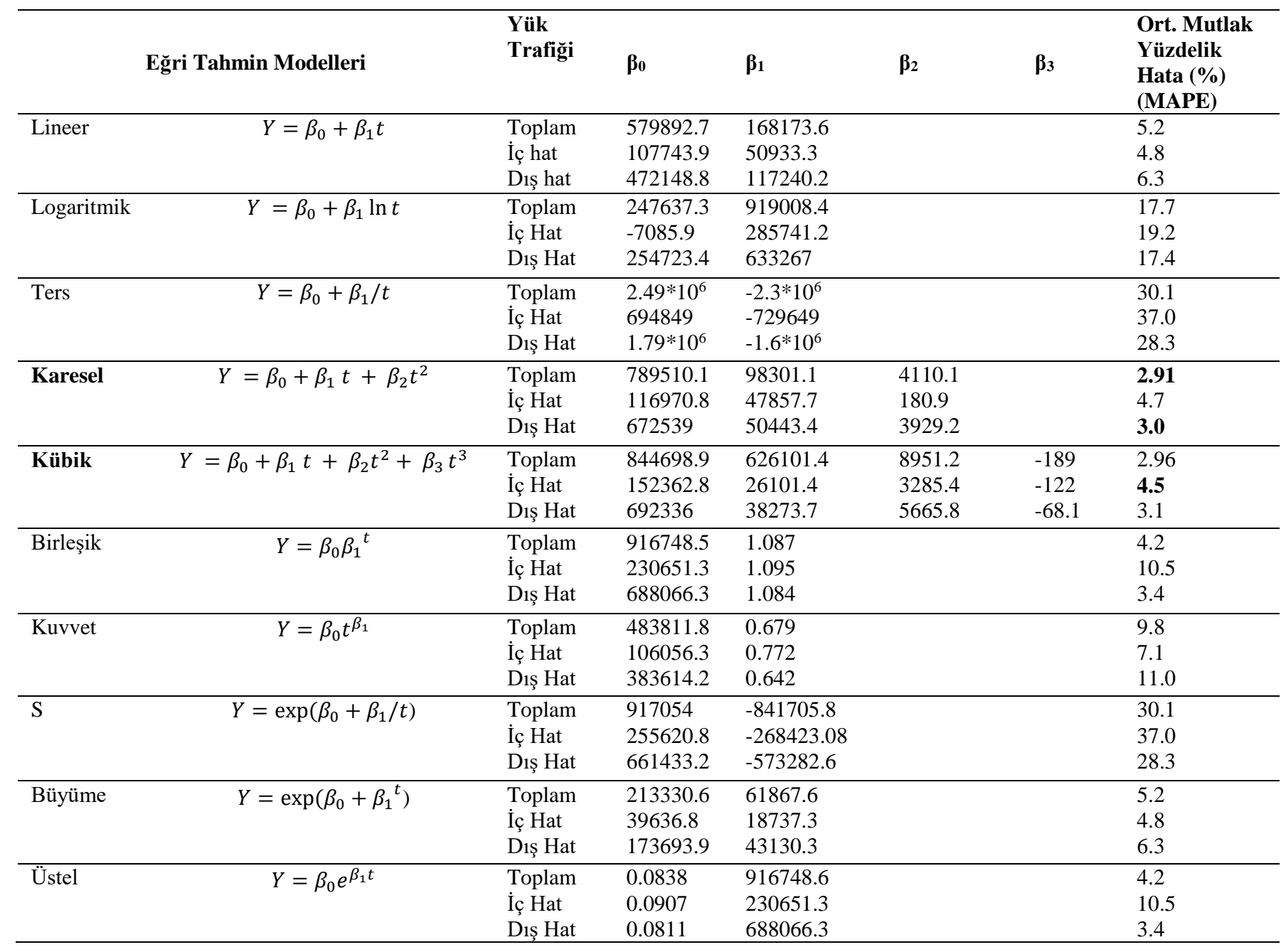

